\title{
Epidemiological Profile of Abnormal Uterine Bleeding at the Gyneco-Obstetric and Pediatric Hospital of Yaounde
}

\author{
Kasia Jean Marie ${ }^{1,2}$, Noa Ndoua Claude Cyrille ${ }^{1,2 *}$, Belinga Etienne ${ }^{1,2}$, Foumane Pascal1,3 \\ ${ }^{1}$ Faculty of Medicine and Biomedical Sciences, University of Yaounde I, Yaounde, Cameroon \\ ${ }^{2}$ Gynaecological Endoscopic Surgery and Human Reproduction Teaching Hospital, Yaounde, Cameroon \\ ${ }^{3}$ Gyneco-Obstetric and Pediatric Hospital of Yaounde, Yaounde, Cameroon \\ Email: *claudenoa@yahoo.co.uk
}

How to cite this paper: Marie, K.J., Cyrille, N.N.C., Etienne, B. and Pascal, F. (2020) Epidemiological Profile of Abnormal Uterine Bleeding at the Gyneco-Obstetric and Pediatric Hospital of Yaounde. Open Journal of Obstetrics and Gynecology, 10, 237-242.

https://doi.org/10.4236/ojog.2020.1020020

Received: October 8, 2019

Accepted: February 11, 2020

Published: February 14, 2020

Copyright $\odot 2020$ by author(s) and Scientific Research Publishing Inc. This work is licensed under the Creative Commons Attribution International License (CC BY 4.0).

http://creativecommons.org/licenses/by/4.0/

\begin{abstract}
Introduction: Abnormal uterine bleeding (AUB) is one of the most commonly encountered symptoms in gynecological consultations. The prognosis is rarely endangered but the impact on the quality of life is sometimes important. Objective: Our objective was to assess the epidemiological profiles of patients consulting for AUB at the Yaounde Gyneco-Obstetrics and Pediatrics Hospital. Methodology: We carried out a descriptive cross-sectional study at the Yaounde Gyneco-Obstetrics and Pediatrics Hospital. We included all women with acute or chronic per vaginal bleeding and we excluded all cases of bleeding in pregnancy, bleeding due to infection, pre pubertal bleeding and the incomplete files. Data were collected from January to May 2019, using a questionnaire, and analyzed using Epi Info version 3.5.4 and SPSS version 7. softwares. Results: A total of 163 patient files were exploited and analyzed. The frequency of AUB in outpatient gynaecology clinics was 3.7\%. AUB patients had a mean age of $36 \pm 12.27$ years and the most represented age group was 30 to 35 years, with $17.1 \%$ cases. Sixty-seven representing $41.1 \%$ patients were married, $23.9 \%$ were civil servants, $23.1 \%$ were tertiary employees, and $40.3 \%$ had secondary level of education. Almost 44.1\% were nulliparous and $53.9 \%$ had unknown HIV status an $83.4 \%$ have never used contraception. Conclusion: The frequency of AUB during gynecological consultations is $3.7 \%$. Those women have an average age of 36 years, most of them are nulliparous and have never use contraception.
\end{abstract}

\section{Keywords}

Morbidity, Menstrual Cycle, Abnormal Uterine Bleeding 


\section{Introduction}

Abnormal Uterine Bleeding (AUB) can be defined as any deviation from the normal menstrual cycle and includes changes in regularity and frequency of bleeding, period of bleeding or amount of blood loss [1]. Abnormal uterine bleeding occurs when either the frequency or quantity of uterine bleeding differs from that mentioned above or the woman has spotting or bleeding between her menstrual periods. It may be caused by a variety of factors. The two most common causes are structural abnormalities of the reproductive system and ovulation disorders. Women who are postmenopausal should seek prompt care from a doctor for any bleeding, as the causes of bleeding and concerns are different from those in women of reproductive age. Although rarely life-threatening, these disorders can significantly affect the quality of life, lead to surgery (including hysterectomy), and ultimately have significant effects on the health system. In addition abnormal uterine bleeding can be encountered at any age from puberty to menopause.

\section{Methods}

We conducted a cross sectional study with a prospective data collection at the Gyneco-obstetric and peadiatric Hospital of Yaounde during a period of 5 months from january to may 2019. We included consenting patients with acute or chronic bleeding and excluded pregnant women, pre-pubertary bleeding and bleeding of infectious origin. We proceeded by probabilistic sampling, including the records of all patients fulfilling the inclusion criteria during the study period. A data sheet was designed and tested prior to use to facilitate the collection of essential information and subsequent data analysis. The sociodemographic variables studied were age, educational level, occupation and the marital status. Reproductive variables were the number of pregnancies, the number of deliveries, the characteristics of the menstrual cycle. The data were analyzed using the software of Epi Info and SPSS version 2.5 end expressed in absolute or relative frequency for qualitative variables, and on average for quantitative variables. Tables and charts were done using the Excel 2007 software.

\section{Ethical Consideration}

We obtained ethical approval from the institutional ethical review board of the Faculty of Medicine and Biomedical Sciences. Authorization was also obtained from the director of study site. The identity and personal details of participants of the study were kept strictly confidential. Only the investigator was able to decipher those codes used in the questionnaires.

\section{Limitations of our Study}

The size of the sample and the absence of anatomo-pathological diagnosis for some case are some limits of this study.

\section{Results}

During the 5 months of our study from January to May 2019, 4321 gynecological 
consultations were recorded, 163 patients were included in our study. The frequency of abnormal uterine abutments (AUB) in gynecological consultations was therefore $3.77 \%$.

The most represented age group was 20 to 30 years old with $17.18 \%$, the average age was $36 \pm 12.27$ years and the extreme age 11 and 71 years old. The majority of patients were married thus $41.1 \%$. Civil servants accounted for $23.93 \%$ (Table 1).

\section{Reproductive Characteristics}

About $33.1 \%$ of the patients had never been pregnant and $28.8 \%$ had more than 2 pregnancies. $44.1 \%$ of the patients had never given birth, $30.06 \%$ had already given birth at least twice. The majority of patients were not menopausal, representing $91.4 \%$. Of these, $65.1 \%$ had an irregular cycle and $27.51 \%$ had heavy bleeding. Only $16.5 \%$ of patients used a contraceptive method among which, more than half used injectable progestins. The majority of patients had unknown HIV status 51.9\% (Table 2).

Abundant menstrual bleeding was the most common reason for consultation with $40.4 \%$, followed by intermenstrual bleeding $22.6 \%$, infrequent menstrual bleeding $16.5 \%$, prolonged menstrual bleeding $12.88 \%$, post coital bleeding and mild menstrual bleeding $0.6 \%$. In $50.9 \%$ of cases there were no associated signs or symptoms. We described other abnormalities like post menopausal bleeding (8.58\%) and intermenstrual bleeding (22.7\%) (Table 3).

Table 1. Distribution according to socio-demographic variables.

\begin{tabular}{|c|c|c|c|}
\hline \multicolumn{2}{|c|}{ Socio-demographic variables } & \multirow{2}{*}{$\begin{array}{c}\text { Number } \mathrm{N}=163 \\
1\end{array}$} & \multirow{2}{*}{$\begin{array}{l}(\%) \\
0.61\end{array}$} \\
\hline \multirow{10}{*}{ Age (years) } & $<15$ & & \\
\hline & {$[15-20[$} & 15 & 9.20 \\
\hline & {$[20-25[$} & 19 & 11.66 \\
\hline & {$[25-30[$} & 28 & 17.18 \\
\hline & {$[30-35[$} & 21 & 12.88 \\
\hline & {$[35-40[$} & 18 & 11.04 \\
\hline & {$[40-45[$} & 25 & 15.34 \\
\hline & {$[45-50[$} & 14 & 8.59 \\
\hline & {$[50-55[$} & 14 & 8.59 \\
\hline & $\leq 55$ & 7 & 4.29 \\
\hline \multirow{5}{*}{ Marital status } & Single & 59 & 36.20 \\
\hline & Married & 67 & 41.10 \\
\hline & Divorced & 2 & 1.23 \\
\hline & Widow & 3 & 1.84 \\
\hline & In relationship & 29 & 17.79 \\
\hline \multirow{5}{*}{ Profession } & Student of secondary education & 45 & 27.60 \\
\hline & Civil servant & 39 & 23.93 \\
\hline & Employee of the tertiary sector & 38 & 23.31 \\
\hline & Household & 35 & 21.47 \\
\hline & Retired & 6 & 3.68 \\
\hline \multirow{4}{*}{ Level of study } & None & 1 & 0.64 \\
\hline & Primary & 36 & 23.08 \\
\hline & Secondary & 63 & 40.38 \\
\hline & University & 56 & 35.90 \\
\hline
\end{tabular}


Table 2. Distribution according to reproductives characteristics.

\begin{tabular}{|c|c|c|c|}
\hline \multicolumn{2}{|c|}{ Reproductives variables } & \multirow{2}{*}{$\begin{array}{c}\text { Number } \\
54\end{array}$} & \multirow{2}{*}{$\begin{array}{r}(\%) \\
33.13\end{array}$} \\
\hline \multirow{4}{*}{ Gestity $(n=163)$} & Nulligeste & & \\
\hline & Primigeste & 24 & 14.72 \\
\hline & Multigeste & 47 & 28.83 \\
\hline & Grandmultigeste & 38 & 23.31 \\
\hline \multirow{4}{*}{ Parity $(n=163)$} & Nulliparous & 72 & 44.17 \\
\hline & Primiparous & 20 & 12.27 \\
\hline & Multiparous & 49 & 30.06 \\
\hline & Grandmultiparous & 22 & 13.50 \\
\hline \multirow{2}{*}{ Cycle $(\mathrm{n}=163)$} & Menopausal & 14 & 8.59 \\
\hline & Non menopausal & 149 & 91.41 \\
\hline \multirow{3}{*}{$\begin{array}{l}\text { Rythm of the } \\
\text { menstrual bleeding }(n=149)\end{array}$} & Regular bleeding & 17 & 11.40 \\
\hline & Irregular bleeding & 97 & 65.10 \\
\hline & Aménorrhea & 35 & 23.48 \\
\hline \multirow{3}{*}{$\begin{array}{l}\text { Volume of the } \\
\text { mestrual bleeding }(n=149)\end{array}$} & Abondant & 41 & 27.51 \\
\hline & Normal & 106 & 71.14 \\
\hline & Light & 2 & 1.34 \\
\hline \multirow{3}{*}{$\begin{array}{c}\text { Fréquency of the } \\
\text { menstrual bleeding }(n=149)\end{array}$} & $<24$ days & 14 & 9.39 \\
\hline & Between 24 to 38 days & 119 & 79.86 \\
\hline & $>38$ days & 16 & 10.73 \\
\hline \multirow{3}{*}{$\begin{array}{c}\text { Duration of the } \\
\text { menstrual bleeding }(n=149)\end{array}$} & $>8$ days & 19 & 12.75 \\
\hline & Between 2 to 8 days & 12 & 8.05 \\
\hline & $<2$ days & 118 & 79.19 \\
\hline \multirow{6}{*}{ Use of Contraception $(n=163)$} & None & 136 & 83.44 \\
\hline & Pills & 1 & 0.61 \\
\hline & Intra-uterin Device & 7 & 4.29 \\
\hline & Injectableprogesteron & 12 & 7.36 \\
\hline & Implant & 2 & 1.23 \\
\hline & Condoms & 5 & 3.07 \\
\hline
\end{tabular}

Table 3. Distribution according to the clinical profile.

\begin{tabular}{|c|c|c|c|}
\hline \multicolumn{2}{|c|}{ Clinical variables } & \multirow{2}{*}{$\begin{array}{c}\text { Number } \\
125\end{array}$} & \multirow{2}{*}{$\begin{array}{l}(\%) \\
76.69\end{array}$} \\
\hline & No abnormality & & \\
\hline Abnormality of the & No Menses & 6 & 9.20 \\
\hline menstrual cycle $(\mathrm{n}=149)$ & Irregular menses & 18 & 14.11 \\
\hline \multirow{3}{*}{$\begin{array}{l}\text { Abnormality of the volume } \\
\text { of menstrual bleeding }(n=149)\end{array}$} & Normal & 82 & 58.90 \\
\hline & Abondant menses & 66 & 40.49 \\
\hline & Light menses & 1 & 0.61 \\
\hline Abnormality of the duration & Normal & 128 & 87.12 \\
\hline of the menstrual bleeding $(n=149)$ & Prolonged menses & 21 & 12.88 \\
\hline \multirow{3}{*}{ Abnormality of the frequency } & Normal & 128 & 78.53 \\
\hline & Toofrequent & 8 & 4.91 \\
\hline & spaniomenorrhea & 13 & 16.56 \\
\hline \multirow{5}{*}{ Other abnormality $(n=163)$} & Absents & 113 & 69.33 \\
\hline & Intermenstrual bleeding & 37 & 22.70 \\
\hline & & & \\
\hline & Post coital bleeding & 1 & 0.61 \\
\hline & post menopausal bleeding & 14 & 8.58 \\
\hline
\end{tabular}




\begin{tabular}{cccc}
\hline & $<18.5$ & 1 & 0.61 \\
& {$[18.5-25[$} & 53 & 32.52 \\
Body mass index & {$[25-30[$} & 72 & 44.17 \\
& {$[30-35[$} & 25 & 15.34 \\
& {$[35-40[$} & 7 & 4.29 \\
& $\geq 40$ & 5 & 3.07 \\
\hline
\end{tabular}

\section{Discussion}

Our study showed that $3.7 \%$ of women suffered from abnormal uterine bleeding (AUB). In a systematic review of menstrual disorders in developed countries, Harlow and Campbell reported a prevalence of $5 \%$ to $15 \%$ of AUB [1]. Nevertheless, H. Kazemijaliseh et al. in Iran have found a prevalence of $30 \%$ which is much higher than our result [2]; the difference can be explained by the fact that at home, except emergency situation, women of childbearing age with AUB consult for the most part in case of with infertility or if the disorders become very important

The women most affected by AUB were those between the ages of 20 and 50 with an average age of 36 years. They accounted for $77.6 \%$ of our sample. Sukhbir $e t$ al. (2013) [3] in his study of abnormal uterine bleeding in pre-menopausal women found that menometrorragia mainly affects women during their period of genital activity. They find a prevalence of $10 \%$ to $25 \%$ among women between 30 and 49 years old and 24\% among 36 - 40 year olds. Moreover, in 2018, Neossi Guena found that women aged 20 to 50, who accounted for $90 \%$, suffered from menorrhagia, which corroborates our results [4]; this is certainly because of the hormonal disorders that are common in this phase of the female life. Dysfunctional uterine bleeding which is the occurrence of uterine bleeding unrelated to structural abnormalities of the uterus or the endometrial lining is a diagnosis of exclusion usually occurs more commonly in the first five years after a woman starts menstruating and as she approaches menopause, but it can occur at any time period. The cause of is anovulation, the absence of ovulation and the orderly secretion of estrogen and progesterone, and may alert the woman and her physician to the fact that she is no longer ovulating normally.

Women who had at least one pregnancy were the most affected by AUB in our study with $14.7 \%$ primigestes, $28.8 \%$ multigestes and $23.3 \%$ large multigestes. Nyingone in 2015 [5] found that $55.8 \%$ of women with genital hemorrhage were multigestes, $29.8 \%$ nulligestes and $14.4 \%$ primigestes. Most of our patients, $83.4 \%$, had never took any method of contraception. Among the patients on contraception, $53.8 \%$ were on hormonal contraception while $29.6 \%$ had an intra-uterine device. Nyingone in 2015 found that, 29 patients out of a sample of 104 or $27.8 \%$ had to take contraceptives which is not far from our results [5], the author specifies that, the oral contraceptive and the IUD are frequent causes of metrorrhagia. Therefore, the use of these contraceptive methods should be sought in case of abnormal uterine bleeding. 
Abundant menstrual bleeding was the most common menstrual disorder with a prevalence of $66 \%$. This disorder is the most serious symptom that can cause or exacerbate anemia and even sometimes life-threatening. Fraser et al. Analyzed the prevalence of heavy menstrual bleeding in women aged 18 - 57 in 5 European countries [6]. In this study 1225 women out of a total of 4506 or $27.1 \%$ suffered from this symptom; which is clearly different of our result. The reasons for this difference can be explained by the fact that this disorder was identified subjectively in our study (by simple questioning of the patient) whereas in the European study the pictorial blood assessment chart was used and represents a more objective quantification tool for menstrual bleeding.

\section{Conclusion}

The frequency of AUB during outpatient gynecology consultations is $3.7 \%$. $\mathrm{Pa}$ tients consulting for AUB had an average age of 36 years and the most represented age group was 30 to 35 years old. Abundant menstrual bleeding was the most common complaint.

\section{Conflicts of Interest}

The authors declare no conflicts of interest regarding the publication of this paper.

\section{References}

[1] Harlow, S.D. and Campbell, O.M. (2004) Epidemiology of Menstrual Disorders in Developing Countries: A Systematic Review. BJOG, 111, 6-16.

[2] Kazemijaliseh, H., Ramezani Tehrani, F., Behboudi-Gandevani, S., Khalili, D., Hosseinpanah, F. and Azizi, F. (2017) A Population-Based Study of the Prevalence of Abnormal Uterine Bleeding and Its Related Factors among Iranian Reproductive-Age Women: An Updated Data. Archives of Iranian Medicine, 20, 558-563.

[3] Sukhbir, S., Carolyn, B., Sheila, D., Nicholas, L. and Wendy, L. (2013) Saignements uterins anormaux chez les femmes pre menopausees. Journal d Obstetrique et $G y$ necologie du Canada, 35, S1-S32.

[4] Neossi Guena, M., Nganyou Piaple, I., Florent, A. and Nkigoum Nana, A. (2018) Apport de l'Echographie dans l'Orientation Diagnostique des Menometrorragies a l'Hopital Regional de Ngaoundere. Health Sciences and Diseases, 19.

[5] Nyingone, S. (2015) Profil epidemiologique et etiologique des hemorragies genitales chez la femme en activite genitale en dehors de la grossesse. These de Doctorat d'Universite, Universite sidi mohammed ben abdellah.

[6] Fraser, I.S., Critchley, H.O., Broder, M. and Munro, M.G. (2011) The FIGO Recommendations on Terminologies and Definitions for Normal and Abnormal Uterine Bleeding. Seminars in Reproductive Medicine, 29, 383.

https://doi.org/10.1055/s-0031-1287662 